\title{
KINERJA KELEMBAGAAN PERLINDUNGAN INDIKASI GEOGRAFIS KOPI KINTAMANI
}

\author{
I Ketut Ardana \\ Pusat Penelitian dan Pengembangan Perkebunan \\ Jl. Tentara Pelajar No. 1 Bogor 16111, Telp. (0251) 8313083 \\ E-mail:ardana_1992@yahoo.com
}

\begin{abstract}
ABSTRAK
Pengakuan terhadap kekhasan produk yang telah teruji memiliki keunggulan kompetitif di pasar komoditas internasional ditetapkan dengan sertifikat Indikasi Geografis (IG). Kopi Kintamani merupakan produk kopi arabika spesial yang memperoleh sertifikat IG tahun 2008. Dibutuhkan dukungan kelembagaan untuk menjaga keberlanjutan IG tersebut. Penelitian kinerja kelembagaan telah dilakukan di kawasan pengembangan kopi Kintamani pada bulan Maret-Mei 2017. Data primer dan sekunder yang terkumpul dari hasil wawancara dengan informan kunci, observasi, dan penelusuran referensi, dianalisis secara deskriptif. Hasil penelitian menunjukkan bahwa dalam upaya perlindungan IG kopi Kintamani, telah dibentuk kelembagaan Masyarakat Perlindungan Indikasi Geografis (MPIG) Kopi Kintamani yang mewadahi interaksi antar pemangku kepentingan: petani sebagai produsen kopi, instansi terkait sebagai pembina, organisasi pendukung, dan pembeli utama. Kinerja kelembagaan perlindungan IG kopi Kintamani telah menjadikan kopi arabika Kintamani sebagai pionir produk kopi bersertifikat IG, menjaga konsistensi penerapan SOP berbaisis IG, dan menumbuhkan optimisme keberlanjutan bagi sebagian besar anggota MPIG. Upaya meningkatkan peran Koperasi Tani MPIG perlu lebih diintensifkan lagi melalui peningkatan kapasitas SDM dan infrastruktur disertai penyegaran kembali komitmen anggota untuk memanfaatkan jasa mediasi pemasaran kopi antara petani dengan pembeli.
\end{abstract}

Kata kunci: kopi arabika, optimisme keberlanjutan, kinerja kelembagaan

\begin{abstract}
Acknowledgment of the specificity of tested products having a competitive advantage in international commodity markets is established with a certificate of Geographical Indication (GI). Kintamani coffee is a special arabica coffee product that received GI certificate in 2008. It takes institutional support to maintain the continuity of GI. Institutional performance research has been conducted in Kintamani coffee development area in March-May 2017. Primary and secondary data collected from interviews with key informants, observation, and reference searching, were analyzed by cross tabulation and descriptively interpreted. The results showed that in the effort of protecting GI of Kintamani coffee, there has been established the institution of Geographical Indication Protection Community (GIPC) which facilitates interaction among stakeholders: farmers as coffee producers, related institutions as builders, and main buyers. The institutional performance of GI Kintamani coffee protection has made Kintamani arabica coffee as a pioneer of GI certified coffee products, maintaining the consistency of the application of GI SOP, and growing sustainability optimism for most GIPC Kintamani coffee members. Efforts to increase the role of GIPC Farmers Cooperative should be further intensified through capacity building of human resources and infrastructure along with refreshment of members' commitment to utilize marketing mediation services between farmers and buyers.
\end{abstract}

Keywords: arabica coffee, continuity optimism, institution performance 


\section{PENDAHULUAN}

Indikasi Geografis (IG) merupakan bentuk perlindungan yang diberikan berkaitan dengan sebuah produk yang menunjukkan : (a) tempat asal daerah, (b) mutu atau ciri-ciri produk yang bersifat khusus, (c) mutu karena berkaitan dengan geografis dan atau manusianya. Perlindungan IG diakui secara multilateral oleh negara anggota WTO (148 negara) termasuk Indonesia, maka Indonesia meratifikasi perjanjian TRIP'S IG kedalam undang-undang Nomor 15 Tahun 2001 tentang Merk. Selanjutnya dijabarkan kembali kedalam PP 51 Tahun 2007 tentang IG (Anonim 2007).

Kopi kintamani sebagai pionir perolehan sertifkat indikasi geografis untuk produk pertanian Indonesia, merupakan produk olahan kopi arabika khas Kintamani. Kintamani yang merupakan salah satu daerah Kecamatan di kabupaten Bangli menjadi sentra produksi dan ikon kopi arabika Bali. Areal kopi arabika Kabupaten Bangli 6.600 Ha dari total 13.150 Ha luas lahan kopi arabika di Provinsi Bali pada tahun 2014. Dari sisi produksi, Kabupaten Bangli juga menjadi daerah penghasil kopi arabika terbesar di Bali dengan jumlah produksi 2.477 ton, sedangkan areal kopi arabika di dua kabupaten penghasil utama lainnya yakni Kabupaten Buleleng tercatat 2.714 hektar dengan produksi 932 ton, dan Kabupaten Badung 1.413 ha dengan produksi 531 ton (Dinas Perkebunan Bali 2015).

Kelembagaan perlindungan indikasi geografis harus memberi manfaat tidak hanya bagi petani, tetapi juga bagi pembangunan wilayah. Penerapan teknologi perlu diimbangi dengan pengelolaan sumberdaya dan kelembagan. Untuk lebih meningkatkan kinerja kelompok maka pola kemitraan sangat diperlukan baik dalam hal penyediaan input, modal maupun pemasaran hasil usahatani (Suharyanto 2006).

Penelitian ini bertujuan untuk mendeskripsikan kinerja kelembagaan dalam menjaga kesinambungan dan konsistensi penerapan sistem produksi kopi kintamani berbasis IG serta manfaatnya bagi petani dan pembangunan wilayah.

\section{METODE PENELITIAN}

Penelitian ini dilakukan pada bulan Maret sampai dengan Mei 2017 di kawasan pengembangan kopi Kintamani, Kabupaten
Bangli, Propinsi bali. Data yang digunakan meliputi data primer dan data sekunder. Data primer dikumpulkan melalui observasi lapang dan wawancara dengan informan kunci: pengurus koperasi tani MPIG, ketua subak abian, dan petani kopi. Penentuan responden menggunakan metode bola salju (snowball sampling)(Nurdiani 2014). Identifikasi awal dimulai dari seorang pengurus MPIG, kemudian berdasarkan hubungan keterkaitan langsung maupun tidak langsung, ditentukan responden ketua subak abian dan petani kopi. Data sekunder dikumpulkan melalui penelusuran data dari Koperasi Tani MPIG dan Dinas Perkebunan serta referensi yang relevan. Data yang terkumpul dianalisis secara deskriptif.

\section{HASIL DAN PEMBAHASAN}

Karakteristik agroekosistem pengembangan kopi Kintamani. Kopi arabika Kintamani dibudidayakan di daerah dataran tinggi sekitar Gunung Batur dengan ketinggian $900 \mathrm{~m}$ diatas permukaan laut. Secara administratif wilayah penghasil kopi Kintamani meliputi tiga kabupaten, yaitu Kabupaten Bangli, Kabupaten Badung, dan Kabupaten Buleleng. Kawasan tersebut memiliki karakteristik ketinggian tempat, curah hujan, suhu udara, maupun karakteristik tanah yang berpengaruh terhadap citarasa kopi Kintamani (MPIG 2007).

\section{Karakteristik Usahatani kopi}

Kintamani. Kekhasan pengelolaan kopi Kintamani selain dibudidayakan pada dataran tinggi adalah penerapan pola tanam tumpangsari dengan tanaman jeruk terintegrasi dengan ternak. Pemetikan kopi dengan cara manual yang cermat dengan persentase gelondong merah minimum 95\%. Kopi gelondong merah di proses dengan cara basah, dengan fermentasi selama 12 jam atau 36 jam dan dikeringkan dengan cara alami lewat cara menjemur (wet process dry hulling). Menurut (Rubiyo et al. 2005), pemberian pupuk kandang dan teknik fermentasi berpengaruh terhadap kualitas dan citarasa kopi arabika. Hasil penelitian (Wahyuni et al. 2013) juga menunjukkan bahwa penentu citarasa yang terbaik dan unik adalah ketinggian tempat, iklim dan pengolahan. Proses pengeringan kopi Kintamani tidak dilakukan di daerah Kintamani, melainkan di daerah Kabupaten Buleleng yang memiliki ketinggian lebih rendah dan dekat ke pantai sehingga suhu 
udaranya lebih panas. Kombinasi antara agroekosistem dan tindakan budidaya tersebut menghasilkan produk kopi Kintamani yang memiliki citarasa khas (MPIG 2007): (1) bebas dari cacat citarasa utama, (2) rasa asam jeruk sesuai dengan lama fermentasi, (3) rasa pahit yang rendah, dan (4) mutu dan intensitas aroma yang kuat dengan rasa buah jeruk.

\section{Kelembagaan perlindungan IG kopi}

Kintamani. Menurut (MPIG 2007),

disamping faktor-faktor alam, penduduk Kintamani, dengan keseharian mereka serta lembaga-lembaga lokal, merupakan bagian penting dari kawasan ini. Para petani jeruk membentuk kelompok kelompok tani pekebun yang dikenal dengan Subak Abian. Kerjasama antar Subak Abian dan dengan pemangku kepentingan lainnya dalam upaya melindungi kopi mereka diformalkan menjadi "Masyarakat Perlindungan Indikasi Geografis (MPIG) Kopi Kintamani Bali" pada tahun 2005 beranggotakan 61 Subak Abian dan 6 perusahaan pengolah kopi Kintamani (Gambar 1).

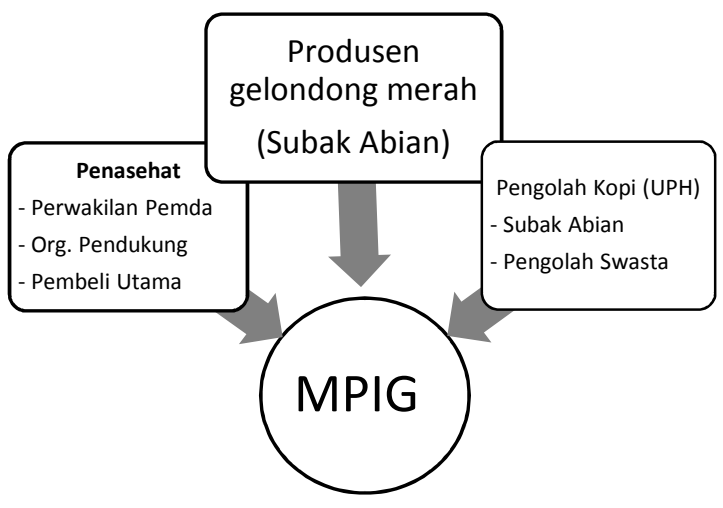

\section{Gambar 1 \\ Komponen penyusun MPIG kopi Kintamani Sumber:MPIG (2007)}

Dalam perkembangannya, MPIG melibatkan: organisasi petani (Koperasi Tani, Subak Abian), instansi pembina (BI, Dinas Perkebunan Prov. Bali, Balai Pengkajian Teknologi Pertanian Bali, dan Pusat Penelitian Kopi dan Kakao Indonesia), mitra (Perbankan, Pembeli). Subak Abian memiliki peran penting dalam MPIG dan bertanggung jawab dalam kehidupan sosial dan religius (Mawardi et al. 2005). Subak Abian selain sebagai produsen gelondong merah, hasil observasi menunjukkan beberapa Subak Abian juga memiliki fasilitas pengolahan dan memproduksi kopi HS atau kopi Ose. Hal tersebut sejalan dengan temuan (Arnawa et al. 2010).
Kopersai Tani MPIG yang didirikan pada tahun 2013 selain memediasi perdagangan kopi antara petani/UPH dengan pembeli (buyer), juga diharapkan menjadi ujung tombak dalam merealisasikan pengembangan klaster kopi Kintamani dengan skema kredit Penguatan Modal Usaha Kelompok (PMUK) dari Bank Indonesia. Selama tiga tahun operasionalisasi Koperasi Tani MPIG nampaknya skema kredit tersebut belum sepenuhnya dimanfaatkan oleh petani kopi anggota MPIG.

\section{Kinerja perlindungan IG kopi}

Kintamani. Kinerja perlindungan IG kopi Kintamani dapat dinilai dari beberapa aspek, yaitu: kiat mencapai sertifikat IG, pembinaan dan pengawasan konsistensi penerapan SOP berbasis IG, serta motivasi menumbuhkan optimisme keberlanjutan.

Sertifikasi IG. Perolehan sertifikat IG pada tahun 2008 merupakan hasil kerja terintegrasi antara petani yang tergabung dalam Subak Abian dibawah bimbingan Dinas Perkebunan Provinsi Bali dengan dukungan hasil riset, asistensi teknis, dan pengembangan jaringan pasar dari Pusat Penelitian Kopi dan Kakao Indonesia (PPKKI). Dinas pertanian kabupaten berperan meningkatkan kemampuan teknis budidaya dan pengelolaan pasca panen, membangun kerjasama dengan berbagai perusahaan ekportir maupun lembaga penelitian untuk memecahkan permasalahan teknis. Kerja terintegrasi serupa juga ditempuh dalam pengembangan kopi spesialti di Indonesia, salah satunya dilaporkan (Neilson 2007) dalam pengembangan kopi di Sulawesi Selatan.

Konsistensi penerapan SOP berbasis

IG. Sejauh ini petani kopi kintamani masih konsisten menerapkan tumpangsari kopi dengan jeruk sebagaimana dicantumkan dalam sertifikasi IG Kopi Kintamani, karena petani yakin kekhasan citarasa kopi kintamani bukan hasil rekayasa genetik, melainkan karena kondisi lingkungan yang timbul dari penerapan sistem tanam yang berlangsung cukup lama. Petani juga menikmati harga premium dari kekhasan citarasa kopi kintamani (Beritasatu 2012). (Teuber 2010) juga menyatakan bahwa IG menjadi penentu harga penting di pasar kopi spesialti.

Meskipun demikian, kendali mutu tetap dilakukan secara berjenjang baik oleh petani (kontrol mandiri), Subak Abian, maupun MPIG kopi Kintamani agar terus dapat 
memenuhi persyaratan yang tertuang dalam Buku Persyaratan IG Kopi Arabika Kintamani Bali (MPIG 2007).

BPTP Balitbangtan Bali bersama Dinas Perkebunan dan Intansi Terkait mengajak petani untuk terus meningkatkan daya saing produk kopi organik, diantaranya melalui diseminasi teknologi pengolahan pupuk cair dari limbah kopi (BPTP Balitbangtan Bali 2017). Selain itu juga memfasilitasi petani kopi melakukan pameran dan mengkampanyekan produk kopi melalui media publikasi. Langkah tersebut memang dibutuhkan untuk memperluas pasar kopi baik di pasar ekspor maupun pasar domestik sebagaimana rekomendasi (Kurniawan 2016).

Sejak tahun 2015 Perusahaan Mitra tertentu membantu pembiayaan selain menerjunkan tenaga Pembina untuk Unit Pengolahan Hasil (UPH). Kelompok yang dibina telah mendapatkan Sertifikat Organik standar USDA NOP (Amerika), standar Uni Eropa, dan Rainforest Alliance untuk Sustainable Agriculture Standard (Adi 2016).

Optimisme keberlanjutan. Pengakuan citarasa kopi Kintamani sebagai kopi organik memberi nilai tambah bagi petani. Hal tersebut sejalan dengan hasil penelitian (Gani 2008) (Gani 2008)bahwa pendapatan petani kopi organik di Dataran Tinggi Gayo lebih besar daripada pendapatan petani kopi anorganik karena perbedaan harga dan produktivitas.

Kesinambungan produksi kopi Kintamani juga menjadi perhatian Pemerintah Korea Selatan ditandai pemberian hibah satu unit alat pengolahan kopi pada tahun 2017 disertai alih teknologi yang diharapkan dapat meningkatkan kapasitas sumberdaya manusia pengelola kopi Kintamani, sehingga dapat meningkatkan kualitas produk. Korea Selatan merupakan negara pengimpor terbesar kopi asal Bali diantara 16 negara pengimpor di dunia (Metrobali 2017).

Manfaat ekonomi perlindungan IG kopi Kintamani juga dapat dinilai dari perannya dalam pembentukan nilai tukar petani (NTP) di Propinsi Bali. Perkembangan harga kopi arabika Kintamani bersama komoditas perkebunan lainnya secara signifikan mempengaruhi NTP (Sutika 2017).

Manfaat paling mendasar keberadaan MPIG kopi Kintamani adalah peran sosial budaya yang dimainkan oleh Subak Abian dalam kehidupan masyarakat. Kelompok ini senantiasa berkontribusi signifikan dalam kegiatan sosial budaya baik secara moral maupun material.

Disisi lain, dari hasil wawancara dengan pengurus Koperasi Tani MPIG terungkap kekhawatiran penurunan volume penyaluran kopi pada tahun 2017 karena terjadinya penurunan luas areal. Faktor utama yang diduga sebagai penyebab penurunan luas areal adalah terjadinya lonjakan harga komoditas sayuran pada tahun 2016, mendorong sebagian petani mengkonversi kebun kopi menjadi kebun sayuran, terutama tanaman kopi tua yang sudah siap diremajakan. Sebagian pertanaman kopi juga dikonversi ke tanaman jeruk dengan pertimbangan bahwa pendapatan usahatani jeruk lebih besar daripada usahatani kopi (Heryana et al. 2016). Penurunan volume penyaluran kopi juga disebabkan sebagian petani menjual hasil kopi langsung kepada pembeli. Hasil penelitian (Arnawa et al. 2010) juga menunjukkan bahwa beberapa Subak Abian memasarkan kopi hasil olahannya kepada perusahaan tertentu dan selanjutnya diekspor atau disalurkan ke café di berbagai kota di Indonesia. Pengurus Koperasi Tani MPIG selama ini memegang komitmen petani menjual $40 \%$ hasil kopi melalui Koperasi. Subak Abian juga berinisiatif melakukan pemasaran kopi bubuk bekerjasama dengan hotel-hotel dan restoran yang ada di sekitar daerah pariwisata Kintamani dan untuk memenuhi kebutuhan masyarakat Kintamani (Wahyuni et al. 2015).

Secara keseluruhan, kesinambungan pembinaan, konsistensi penerapan SOP, perkembangan ekspor, dan manfaat sosial budaya telah menumbuhkan optimisme keberlanjutan di kalangan anggota MPIG. Pengurus Koperasi Tani MPIG mengungkapkan bahwa sebagian besar anggotanya mendukung kinerja MPIG. Hal tersebut juga tercermin dari hasil penelitian Wahyuni dan Kariada (2015) bahwa penilaian anggota MPIG berdasarkan skala likert mencapai 91,48 \% dengan kategori "sangat setuju" terhadap keberlanjutan peran MPIG dalam pola kemitraan kopi Kintamani. Jadi keberadaan kelembagaan MPIG diharapkan dapat memberikan manfaat bagi kebutuhan masyarakat secara utuh sebagaimana dikemukakan (Suradisastra 2006).

\section{KESIMPULAN DAN SARAN}

Kinerja kelembagaan perlindungan indikasi geografis kopi Kintamani telah menjadikan kopi arabika Kintamani sebagai pionir produk kopi bersertifikat IG, menjaga 
konsistensi penerapan SOP berbaisis IG, dan menumbuhkan optimisme keberlanjutan bagi sebagian besar anggota MPIG kopi Kintamani.

Peran Koperasi Tani MPIG perlu lebih diintensifkan lagi disertai penyegaran kembali komitmen anggota untuk memanfaatkan jasa mediasi pemasaran kopi antara petani dengan pembeli.

\section{DAFTAR PUSTAKA}

Adi. 2016. Panen Kopi Robusta dan Arabika Buleleng Meningkat.

Anonim. 2007. Peraturan Pemerintah Republik Indonesia Nomor 51 Tahun 2007 Tentang Indikasi Geografis. Hukumonline [Internet].:1-22.

Arnawa IK, Martiningsih NGAGE, Budiasa IM, Sukarna IG. 2010. Peningkatan Kualitas dan Kuantitas Kopi Arabika Kintamani dalam Upaya Meningkatkan Komoditas Ekspor Sektor Perkebunan. Maj Apl Ipteks Ngayah. 1:63-70.

Beritasatu. 2012. Harga Kopi Bali Lebih Mahal Dibanding Kopi Dunia.

BPTP Balitbangtan Bali. 2017. BPTP Balitbangtan Bali Kuatkan Daya Saing Komoditas Kopi [Internet]. Available from: file:/// D:/BPTP Balitbangtan Bali Kuatkan Daya Saing Komoditas Kopi.htm

Dinas Perkebunan Bali. 2015. Kopi Arabika Kintamani Masuk Unggulan Komoditi Nasional [Internet]. Available from: http://www.disbun.baliprov.go.id/berita/d etail/74-kopi-arabika-kintamani-masukunggulan-komoditi-nasional

Gani AA. 2008. Analisis Komparatif Pendapatan Petani Kopi Organik dan Petani Kopi Anorganik di Dataran Tinggi Gayo Nanggroe Aceh Darussalam. J Ilm ESAI [Internet]. 2(2).

Heryana IPA, Sudarma IM, Putra IGSA. 2016. Perbandingan Pendapatan antara Usahatani Kopi dan Usahatani Jeruk di Desa Serai Kecamatan Kintamani Kabupaten Bangli. E-Jurnal Agribisnis dan Agrowisata. 5:1-9.

Kurniawan BPY. 2016. Analysis and priority of competitive advancement for arabica coffee-Java coffee bondowoso in Indonesia. Int J Appl Bus Econ Res. 14:965-979.

Mawardi S, Wibawa a, Avelino J, Perriot J-J, Jacquet M, Sautier D, De Taffin G, Sallée
B, Lelong C, Ribeyre F. 2005.

Developing a geographical indication for Arabica coffee in Bali : Description of the "Terroir" of Kintamani. 20th Int Conf Coffee Sci.:922-928.

Metrobali. 2017. Ekspor Kopi Bali ke Korea Selatan 14 Ribu Ton Lebih _ [Internet]. Available from: http://metrobali.com/ 2017/ 01/10/ekspor-kopi-bali-ke-koreaselatan-14-ribu-ton-lebih/

MPIG. 2007. Buku Persyaratan Indikasi Geografis Kopi Arabika Kintamani Bali.

Neilson J. 2007. Institutions, the governance of quality and on-farm value retention for Indonesian specialty coffee. Singap J Trop Geogr. 28:188-204.

Nurdiani N. 2014. Teknik Sampling Snowball Dalam Penelitian Lapangan. ComTech [Internet]. 5:1110-1118.

Rubiyo, Kartini L, Agung IMS. 2005. Pengaruh Dosis Pupuk Kandang dan Lama Fermentasi terhadap Mutu Fisik dan Citarasa Kopi Arabika Varietas S 795 di Bali. J Pengkaj dan Pengemb Teknol Pertan. 8:250-260.

Suharyanto. 2006. Analisis kelembagaan model sistem integrasi tanaman kopi - ternak kambing [Internet]. :145-149. Available from: https://kelembagaandas.wordpress. com/kelembagaan-agribisnis/suharyanto/

Suradisastra K. 2006. Revitalisasi Kelembagaan Untuk Percepatan Pembangunan Sektor Pertanian Dalam Otonomi Daerah. Anal Kebijak Pertan [Internet]. 4(4):281-314.

Sutika IK. 2017. Perkebunan Bentuk NTP Bali Naik 1,15 Persen.

Teuber R. 2010. Geographical Indications of Origin as a Tool of Product Differentiation: The Case of Coffee. J Int Food Agribus Mark [Internet]. 22:277298.

Wahyuni E, Karim A, Anhar A. 2013. Analisis Citarasa Kopi Arabika Oganik pada Beberapa Ketinggian Tempat dan Cara Pengolahannya di Dataran Tinggi Gayo. J Manaj Sumberd Lahan. 2(3).

Wahyuni MA, Wijaya KP, Kariada IK. 2015. Distribusi Pemasaran Produk Agroindustri Kopi Bubuk Arabika Madu di Kelompok Tani Harapan Maju Dusun Petung, Desa Batur Tengah, Kintamani, Bangli. Bul T eknologi dan Inf Pert anian. 13:6-11. 